\title{
Alternativas para o tratamento de efluentes da INDÚSTRIA GALVÂNICA
}

\section{Alternatives for the galvanic WASteWATER tREATMENT}

\begin{abstract}
ARTUR PEREIRA NETO
Engenheiro Químico, aluno do Programa de Pós-Graduação em Engenharia Química da UFMG

JOANA DE SOUZA BRETZ

Engenheira Química, aluna do Programa de Pós-Graduação em Engenharia Química da UFMG

\author{
FERNANDO SILVA MAGALHÄES \\ Técnico em Química
}

MARCELO BORGES MANSUR

Doutor em Engenharia Química. Professor Adjunto do Departamento de Engenharia Metalúrgica e de Materiais da Universidade Federal de Minas Gerais

\section{SONNIA DENISE FERREIRA ROCHA}

Doutora em Engenharia Metalúrgica e de Minas. Professora Associada do Departamento de Engenharia de Minas da Universidade Federal de Minas Gerais
\end{abstract}

Recebido: 27/02/07 Aceito: 21/03/08

\begin{abstract}
RESUMO
Os métodos de precipitação química, cristalização e extração líquido-líquido foram aplicados visando propor alternativas para o tratamento de efluentes líquidos gerados pela indústria de galvanoplastia. Efluentes de diversas empresas do setor, localizadas no estado de Minas Gerais (Brasil), foram coletados e caracterizados. O efluente estudado, proveniente de empresa de galvanização de zinco a quente, continha cerca de $90 \mathrm{~g} / \mathrm{L}$ de ferro total, $35 \mathrm{~g} / \mathrm{L}$ de zinco e menores quantidades de $\mathrm{Al}$, Ni e $\mathrm{Cu}$, em meio ácido clorídrico $(\mathrm{pH}=0,6)$. A separação seletiva entre ferro e zinco não se mostrou eficiente por precipitação, sendo a técnica adequada somente no tratamento do efluente, ao contrário da cristalização e extração líquido-líquido utilizando-se TBP como agente extratante. A integração destas técnicas ainda requer estudos mais detalhados visando à otimização de custos e das condições operacionais.
\end{abstract}

PALAVRAS-CHAVE: Indústria galvânica, tratamento de efluentes, separação zinco e ferro, precipitação, cristalização, extração líquido-líquido.

\section{INTRODUÇÃO}

O tratamento de superfícies metálicas visando-se a alteração de suas propriedades é prática industrial comum no mundo e de destaque no estado de Minas Gerais, Brasil. A indústria galvânica possibilita o recobrimento de superfícies metálicas com metais diversos, permitindo, assim, principalmente um aumento na resistência à corrosão da peça. Desta forma, peças de metais mais baratas tornam-se mais resistentes e adquirem, como conseqüência, uma melhor aparência, o que aumenta o seu valor agregado. Por outro lado, os processos produtivos associados a essas atividades industriais contemplam diversas etapas de processamento de superfícies metálicas em contato com soluções aquosas (ácidas e básicas) que levam, inevitavelmente, à geração de efluentes líquidos contendo uma grande variedade de metais pesados dissolvidos.

O processo galvânico consiste, inicialmente, de uma etapa de desengraxe da superfície metálica utilizando-se soluçōes alcalinas concentradas. Nesta etapa, tem-se por objetivo a remoção de óleos, graxa e outros orgânicos residuais aderidos à superfície das peças devido aos processos de laminação, transporte e 
outros que possam prejudicar o recobrimento da peça. Para tal, banhos de soda $(\mathrm{NaOH})$ são geralmente empregados, principalmente em função do baixo custo e da sua boa ação desengraxante. Em seguida, a peça é submetida a uma etapa de decapagem ácida, utilizandose principalmente banhos clorídricos $(\mathrm{HCl})$ para a remoção de resíduos de soldas e óxidos presentes na peça. Nesta etapa, as peças são submersas nas soluçôes ácidas por tempo determinado, de acordo com a necessidade específica de cada uma. Outros ácidos tais como o ácido nítrico $\left(\mathrm{HNO}_{3}\right)$, ácido sulfúrico $\left(\mathrm{H}_{2} \mathrm{SO}_{4}\right)$ e ácido fluorídrico (HF) também podem ser utilizados para fins mais específicos. Assim, uma vez preparadas, as peças são submetidas à deposição de finas camadas metálicas sobre suas superfícies. Esse recobrimento é efetuado por meio químico e/ou eletroquímico, a partir de soluções aquosas dos metais a serem depositados, ou até mesmo camadas mais espessas, a partir do próprio metal fundido. Após cada etapa do processo galvânico, as peças são lavadas diversas vezes via imersão das mesmas em banhos de lavagens. Dessas etapas provém o maior volume de efluentes contendo metais pesados, que deve ser submetido a tratamento prévio ao seu descarte.

É importante ressaltar que uma prática industrial baseada nos princípios de redução de emissóes na fonte, reciclagem e reaproveitamento deve sempre orientar as ações de operações e processos. Diversas técnicas podem ser utilizadas para retirar metais de soluções, tornando os efluentes adequados para o seu lançamento em cursos d'água. Técnicas tais como precipitação química, coagulação-floculação, flotação, trocaiônica, adsorção, filtração por membranas, extração líquido-líquido estão entre as mais investigadas (Kurniawan, 2006; Wei, 2005; Schugerl et al, 1996; Csicsovszki et al, 2005; Tomaszewska et al, 2001; Jandová et al, 2002, Zhou et al, 1999), sendo que cada uma destas possui vantagens e desvantagens, logo a escolha do processo de tratamento é balizada pela sua viabilidade técnica e econômica.

A precipitação química é indubitavelmente o método mais utilizado para o tratamento de efluentes da indústria galvânica apontado na literatura (Kurniawan, 2006; EPA, 2000; Zhou et al, 1999). As principais vantagens da precipitação química estão no fato da tecnologia e agentes alcalinizantes estarem disponíveis, especialmente a cal, que é de custo muito baixo. Além disso, a operação e manutenção dos equipamentos é relativamente simples se o objetivo é estritamente tratar o efluente. Esse método convencional de tratamento de efluentes industriais contendo metais em solução aquosa consiste na elevação do $\mathrm{pH}$ do meio até valores acima de 9,0, promovendo condiçôes de baixa solubilidade dos hidróxidos dos metais que se precipitam sob a forma de hidróxidos ou complexos diversos. Devido às condiçôes de elevada supersaturação, os sólidos formados são coloidais e requerem etapas de coagulação/floculação para sua separação da fase líquida residual. Uma quantidade considerável de precipitado (lama) usualmente classificado segundo a norma ABNT-NBR 10.004 como resíduo classe $\mathrm{I}$, perigoso e tóxico, é gerado como resíduo do processo de tratamento. A disposição final da lama gerada deve ser realizada em aterros industriais controlados ou, quando possível, pode ser enviada para co-processamento em fornos de clínquer, o que representa custos significativos de implantação e manutenção, consistindo, ainda, em um impacto ambiental negativo considerável.

As principais desvantagens da precipitação química estão relacionadas com a ocorrência de reaçôes paralelas em função da composição química do efluente e da necessidade de se estabelecer a dose do agente alcalinizante através de testes de jarros. A superdosagem do álcali pode reduzir a eficiência do tratamento devido à formação de hidroxocomplexos solúveis. Adicionalmente, para uma eficiente etapa de separação sólido-líquido, é necessária uma etapa subseqüente de coagulação-floculação, o que pode elevar os custos do processo como um todo (EPA, 2000).

Em Minas Gerais, as empresas de grande porte efetuam o tratamento de seus efluentes tendo como meta atingir os padrōes de lançamento de efluentes líquidos vigentes no estado e definidos pela Deliberação do COPAM 10/86. Ao contrário, pequenas empresas, normalmente localizadas em áreas urbanas, estabelecem um acordo com a COPASA (NT 187/2, 2002) para lançar seus efluentes em uma rede coletora especial e pagam uma taxa pelo lançamento em função da carga poluidora. A COPASA trata esses efluentes em suas unidades de tratamento de água. Entretanto, para que o efluente seja lançado, a empresa deve também atender a requisitos de concentração pré-estabelecidos em contrato específico.

Nas últimas décadas, verificou-se uma tendência crescente no tratamento dos efluentes, associada à recuperação de compostos e/ou metais presentes, na forma de subprodutos de alto valor agregado com base nos princípios de Produção Mais Limpa $(\mathrm{P}+\mathrm{L})$. As técnicas disponíveis para tratar os efluentes conferindo à água condiçôes de reciclagem ao processo, tais processos de troca iônica, extração líquido-líquido, filtração por membranas (osmose reversa, microfiltração, ultrafiltração, nanofiltração) vêm alcançando espaço (Kurniawan et al, 2006). Essas técnicas apresentam custos de investimento mais elevados, além de uma tecnologia específica para cada tipo de efluente, o que ainda tem inviabilizado a maioria das aplicações principalmente em empresas de pequeno e médio porte, resultando no direcionamento do processo para o estrito tratamento do efluente, sem aplicação integral de conceitos de P+L.

Nesse sentido, o presente trabalho tem como objetivo a aplicação de tecnologias de tratamento capazes de minimizar a geração dos resíduos industriais através da recuperação econômica de compostos e metais presentes. Para tal, realizou-se, inicialmente, uma avaliação do parque industrial de galvanoplastia no estado de Minas Gerais, de forma a identificar as características típicas dos efluentes gerados. Em seguida, após a seleção de um tipo de efluente em particular, representativo de uma parcela do setor, as técnicas de precipitação, cristalização e extração líquido-líquido foram aplicadas para apontar possíveis rotas alternativas ao seu tratamento, visando, inclusive, a reutilização dos metais presentes no efluente.

\section{METODOLOGIA}

\section{Caracterização do setor e seleção do efluente a ser estudado}

O setor de galvanização no estado de Minas Gerais foi caracterizado quanto ao tamanho, número e localização das empresas, além da identificação dos principais metais constituintes dos efluentes gerados. Esta etapa foi realizada através de pesquisas no CRQ- 
MG (Conselho Regional de Química) e na FEAM (Fundação Estadual de Meio Ambiente), além de busca em lista telefônica. Várias empresas foram contatadas e visitadas. Além do preenchimento de um questionário técnico incluindo informações cadastrais das empresas, efetuou-se, quando possível, a coleta de amostras em pontos distintos do processo. Nesta primeira etapa foram coletadas amostras simples de 1 Litro. Foram levantados dados referentes ao processo industrial de cada empresa visitada, com ênfase nos efluentes gerados e que seriam utilizados nas etapas subseqüentes do trabalho. Os efluentes coletados nas visitas foram submetidos à caracterização preliminar de sua composição química. Foram identificados dois efluentes típicos para representar a natureza do universo do parque industrial mineiro, a depender do porte da empresa e da operação de recobrimento realizada. Foi realizada a amostragem composta dos efluentes selecionados durante uma semana, 1 litro ao dia, totalizando aproximadamente sete litros de efluente (amostra composta). Sub-amostras foram retiradas do efluente total e, então, submetidas à análise química completa, utilizando-se técnicas de espectrofotometria de fluorescência de raios-X, espectrofotometria de absorção atômica e de espectrofotometria de absorção molecular, além de técnicas convencionais de via úmida. Esta etapa do estudo foi realizada em parceria com o CDTN-CNEN, de Belo Horizonte, MG.

\section{Ensaios de redução do conteúdo de metais dissolvidos no efluente selecionado}

Ensaios de precipitação com diversos agentes alcalinos, cristalização por evaporação e de extração líquidolíquido foram realizados. O estudo teve dois focos distintos: separação seletiva, quando possível, e/ou tratamento do efluente, envolvendo a remoção dos metais nos níveis exigidos pela legislação. Os ensaios foram realizados utilizando-se o efluente caracterizado como típico de empresas de pequeno porte, gerado no processo de galvanização com zinco, uma vez que as empresas de maior porte possuem suas próprias estações de tratamento. Por esta razão, os métodos de tratamento estudados precisam ser eficientes, de baixo custo, e passíveis de possível instalação em pequena escala.

\section{Ensaios de precipitação}

Os ensaios de precipitação foram realizados em um reator de vidro com capacidade de $1 \mathrm{~L}$, em temperatura constante de $28^{\circ} \mathrm{C}$ e agitado mecanicamente empregando-se um impelidor de vidro do tipo marina. A agitação variou de 450 a $800 \mathrm{rpm}$, dependendo $\mathrm{da}$ viscosidade da polpa, de forma a se obter uma boa mistura do meio. Os seguintes agentes precipitantes foram empregados: soluções de $\mathrm{NaOH}$ (0,5\%p/v, $1 \% \mathrm{p} / \mathrm{v}, 5 \% \mathrm{p} / \mathrm{v}$ e $30 \% \mathrm{p} / \mathrm{v})$, $\mathrm{NH}_{4} \mathrm{OH}(50 \% \mathrm{p} / \mathrm{v})$, além de polpas de $\mathrm{CaO}$ e $\mathrm{MgO}$. Em todos os ensaios, o volume inicial de efluente alimentado foi de $300 \mathrm{~mL}$ e o $\mathrm{pH}$ original do efluente ajustado de $\mathrm{pH}=0,6$ para $\mathrm{pH}=2,0$, uma vez que os hidróxidos de zinco e ferro não precipitam em valores de $\mathrm{pH}$ abaixo de 2. Os agentes precipitantes foram, então, adicionados lentamente variando-se o pH de 2 até 9 (em média), com intervalos de, aproximadamente, uma unidade de $\mathrm{pH}$. Após a estabilização do sistema, em cada valor de $\mathrm{pH}$, uma amostra da polpa foi coletada $(10 \mathrm{~mL})$ e filtrada em membrana de éster de celulose (diâmetro de poro $38 \mu \mathrm{m}$ ). As amostras foram acidificadas para garantir a estabilização das espécies em solução, evitando-se, assim, à precipitação posterior dos hidróxidos metálicos. As concentrações de ferro e zinco foram determinadas por espectrofotometria de absorção atômica (marca GBC 932 plus), e o pH da solução aquosa medido por um $\mathrm{pHmetro}$ digital modelo Digimed DM-20. O percentual de precipitação (\%Prec.) de ferro ou zinco foi calculado por:

$\%$ Prec. $=100 c \frac{\mathrm{m}_{\mathrm{Me}, \text { inicial }}-\mathrm{m}_{\mathrm{Me} \text {.final }}}{\mathrm{m}_{\mathrm{Me} \text {, inicial }}} \mathrm{n}$

em que $m_{M e, \text { inicial }}$ é a massa inicial de metal na solução e $m_{\text {Me,final }}$ a massa de metal presente na solução após a precipitação.

\section{Ensaios de cristalização}

Os ensaios foram realizados em um reator de vidro com $2 \mathrm{~L}$ de capacidade. O efluente foi previamente filtrado em papel de filtro faixa azul, adicionado ao reator, e aquecido em uma chapa elétrica para evaporar a água contida no licor. Desta maneira, obteve-se uma solução saturada no cloreto de ferro, que é mais insolúvel que o cloreto de zinco. Em seguida, a solução foi resfriada à temperatura ambiente para cristalizar primeiramente o ferro sob a forma de cloreto ferroso tetrahidratado, que foi recuperado em seqüência por filtração. Amostras da solução aquosa foram coletadas e analisadas por absorção atômica. O sal obtido foi redissolvido em água destilada, e o teor de ferro e zinco analisados para se avaliar a pureza do sal obtido.

\section{Ensaios de extração líquido-líquido}

Os ensaios foram realizados contactando-se o efluente estudado com uma solução orgânica contendo trifosfato de butila (TBP, marca Merck, pureza superior a 98\%) como extratante, dissolvido em querosene alifático comercial (Exxsol D-80), em concentraçôes variando de 25 a $100 \%$ v/v de TBP. As soluções foram contactadas em um reator de vidro agitado de $1 \mathrm{~L}$ de capacidade, sob agitação constante, utilizando-se um impelidor de vidro de três pás (200 rpm). Os ensaios de equilíbrio foram conduzidos à temperatura ambiente, em razões volumétricas aquosa/orgânica (A/O) variadas, durante 20 minutos. A duração dos ensaios foi definida em ensaios preliminares e o $\mathrm{pH}$ da solução aquosa monitorado durante toda a sua execução. Após a contactação, a agitação foi interrompida para a separação das fases e coleta de amostras da fase aquosa para determinação da concentração dos metais ferro e zinco. O conteúdo dos metais na fase orgânica foi calculado por balanço de massa.

\section{RESULTADOS}

\section{Caracterização do setor e efluentes típicos}

Foram identificados, no estudo, um total de 154 empresas, distribuídas em 38 cidades no estado de Minas Gerais. Verificou-se que quase 60\% das empresas localizam-se no parque industrial da região metropolitana de Belo Horizonte, incluindo Contagem e Betim, como mostrado na Figura 1. Apesar dessa concentração, as pequenas e microempresas, em alguns casos, localizam-se relativamente distantes uma das outras, o que dificulta uma coleta conjunta dos efluentes para tratamento único. Este aspecto aponta para a implantação de pequenas estações de tra- 
tamento. Assim, os processos de tratamento dos efluentes a serem propostos para este setor devem apresentar custo relativamente baixo, e possibilidade de implantação em cada empresa, individualmente ou em pequenos grupos de empresas localizadas relativamente próximas, focalizando o tipo de efluente produzido pelo grupo.

A caracterização preliminar dos efluentes coletados nas empresas visitadas revelou a presença dos seguintes metais pesados, em maiores proporçōes: zinco, ferro, cromo, níquel, alumínio, cobre, etc. Tais efluentes foram agrupados com relação à concentração e o tipo dos metais e ácidos presentes em dois efluentes característicos do setor: efluente tipo 1, que consiste de licores clorídricos contendo elevadas concentrações de ferro e zinco, e efluente tipo 2, que são licores contendo níquel, cromo e ácidos diversos como nítrico e fluorídrico, principalmente. $\mathrm{O}$ efluente tipo 1 contém metais com menor valor agregado, sendo este mais freqüentemente gerado por empresas de pequeno e médio porte no processo de galvanização com zinco, ao passo que o efluente tipo 2 contém metais e ácidos com maior valor agregado, sendo este gerado mais comumente em empresas de maior porte e em processos de recobrimento como cromagem, niquelagem, etc. Assim, para o presente estudo, utilizou-se somente o efluente tipo 1 , cuja composição química detalhada é apresentada na Tabela 1 .

O efluente tipo 1 consiste de uma solução extremamente ácida de natureza clorídrica, contendo essencialmente zinco e ferro como principais constituintes metálicos. A quantidade de outros metais como alumínio, níquel e cobre é relativamente baixa. $\mathrm{O}$ ferro encontra-se presente no efluente predominantemente sob a forma $\mathrm{Fe}^{2+}$ $(97,6 \%)$. Dessa forma, para o tratamento do efluente e a recuperação dos metais constituintes, os métodos de separação por precipitação, cristalização e extração líquido-líquido foram aplicados ao efluente, visando separar zinco e ferro, e/ou apenas tratar o líquido para possibilitar o seu descarte.

\section{Precipitação química}

Dentre os agentes precipitantes passíveis de utilização, os agentes alcalinos tais como óxido de cálcio (cal) e hidróxido de sódio (soda) são os mais

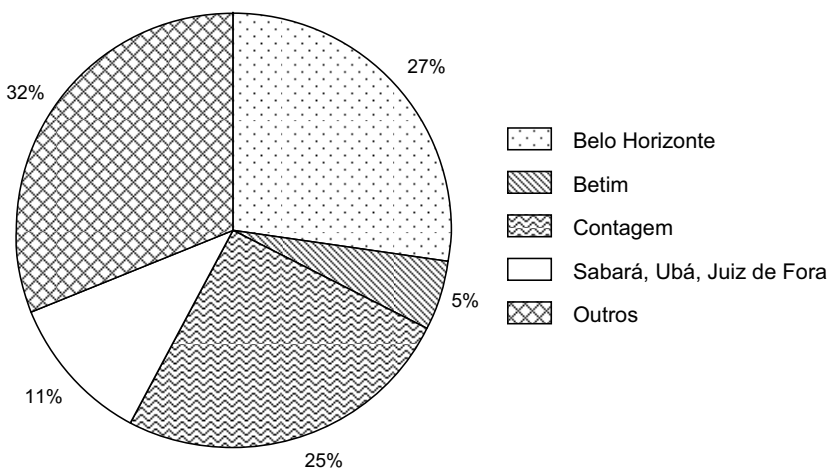

Figura I - Distribuição regional das empresas de galvanoplastia em Minas Gerais

Tabela I - Composição química do efluente industrial tipo |

\begin{tabular}{cc}
\hline Concentração & Valor \\
\hline $\mathrm{Fe}_{\text {total }(\mathrm{g} / \mathrm{L})}$ & 92,2 \\
$\mathrm{Fe}^{2+}(\mathrm{g} / \mathrm{L})$ & 90,0 \\
$\mathrm{Fe}^{3+}(\mathrm{g} / \mathrm{L})$ & 2,2 \\
$\mathrm{Zn}(\mathrm{g} / \mathrm{L})$ & 70,2 \\
$\mathrm{Al}(\mathrm{mg} / \mathrm{L})$ & 30,0 \\
$\mathrm{Ni}(\mathrm{mg} / \mathrm{L})$ & $<0,5$ \\
$\mathrm{Cu}(\mathrm{mg} / \mathrm{L})$ & $<0,5$ \\
$\mathrm{pH}$ & 0,6 \\
\hline
\end{tabular}

comumente utilizados na indústria para o tratamento de efluentes. Sulfetos também podem ser empregados (Peters et al, 1984), mas a elevada toxidez da lama vem restringindo seu uso. $\mathrm{O}$ hidróxido de magnésio é outro agente precipitante que também pode ser utilizado (Ribeiro e Rocha, 2006; Teringo III, 1987), mas este ainda não alcançou espaço de mercado devido a questôes tecnológicas e econômicas, embora sua utilização venha sendo investigada.

Os ensaios de precipitação foram realizados via adição estagiada dos agentes precipitantes ao efluente. Uma análise do diagrama Eh-pH para o sistema $\mathrm{Fe}-\mathrm{H}_{2} \mathrm{O}$ a $25^{\circ} \mathrm{C}$, construído a partir de dados termodinâmicos deste sistema utilizando-se o software HSC- Chemistry, versão 4.0 apresentado na Figura 2 indica que o hidróxido de ferro (II) se forma em valores de $\mathrm{pH}$ bem acima daqueles requeridos para a formação de hidróxido de ferro (III). Como verificado na Tabela 1, o ferro contido no efluente se encontra praticamente sob a forma bivalente $\left(\mathrm{Fe}^{2+}\right)$, cuja faixa de precipitação como hidróxido é muito próxima à de precipitação do hidróxido de zinco. Assim, teoricamente, não seria possível separar ferro (II) de zinco por precipitação como hidróxidos, logo, para que estes metais sejam separados, faz-se necessário, a priori, que o ferro esteja majoritariamente sob a forma de ferro (III). Com isso, é necessária a inclusão de uma etapa adicional de oxidação do ferro bivalente a trivalente. Neste contexto, os ensaios de precipitação foram realizados utilizando-se tanto o efluente conforme recebido (contendo essencialmente $\mathrm{Fe}^{2+}$ ) quanto o efluente oxidado (contendo ferro sob a forma de $\mathrm{Fe}^{3+}$ ). Para tal, antes dos ensaios de precipitação, fez-se a oxidação total do $\mathrm{Fe}^{2+}$ a $\mathrm{Fe}^{3+}$ utilizando-se peróxido de hidrogênio $\left(\mathrm{H}_{2} \mathrm{O}_{2}\right)$, de maneira a avaliar a possibilidade de precipitação seletiva do $\mathrm{Fe}^{3+}$ como $\mathrm{Fe}(\mathrm{OH})_{3}$ e sua separação do zinco.

As Figuras 3(a) e 3(b) apresentam, respectivamente, as curvas de precipitação obtidas para o zinco e ferro em função da elevação do $\mathrm{pH}$ da fase aquosa utilizando-se os diversos agentes precipitantes sob estudo. Verificou-se que todos os agentes precipitantes investigados são adequados somente para o tratamento total do efluente. Em outras palavras, o método de precipitação, 
nas condiçōes investigadas neste estudo, propicia apenas a remoção conjunta dos metais presentes no efluente de maneira a tratar o efluente visando o seu descarte. Verificou-se que ambos os metais são efetivamente precipitados em valores de pH superiores a 7,0, sem que haja uma separação efetiva entre estes. Tem-se, ainda, que a oxidação prévia do ferro presente no efluente não resultou em uma separação eficiente de ferro e zinco. $\mathrm{Na}$ verdade, este resultado considerado insatisfatório pode ter sido provocado pela concentração elevada dos metais na solução, que deve ter ocasionado a co-precipitação do zinco conjuntamente com a do ferro, daí a baixa seletividade na separação entre estes metais. Com base nestes resultados, tem-se que este método de tratamento é eficiente apenas no tratamento da solução aquosa, sendo inadequado como alternativa para a recuperação seletiva dos metais. Portanto, para o tratamento de efluentes de galvanização de zinco por precipitação, recomenda-se o uso do agente precipitante em soluções concentradas, de modo a gerar uma menor variação no volume final do efluente a ser lançado.

A precipitação conjunta de ferro e zinco constitui uma alternativa para o tratamento do efluente, contudo não produz uma lama capaz de ser facilmente reaproveitada. A precipitação seletiva dos metais não se mostrou tecnicamente viável devido às elevadas concentrações dos metais (que favorece a co-precipitação dos mesmos) e, também, devido à proximidade dos $\mathrm{pH}$ 's de precipitação dos hidróxidos de ferro (II) e hidróxido de zinco. Verificou-se que a baixa seletividade na separaçáo $\mathrm{Fe} / \mathrm{Zn}$ se torna ainda menor quando soluçôes mais concentradas no agente precipitante são empregadas. Isso se deve às dificuldades operacionais em se manter uma mistura perfeita do meio, o que implica na geração de elevados níveis de supersaturação local (relação entre a concentração da espécie em precipitação e sua solubilidade, na temperatura de trabalho), acarretando em uma precipitação simultânea dos dois metais. Esse problema de ineficiência de mistura se torna de maior proporção quando se passa da escala de laboratório para a escala industrial. De uma maneira geral, após a precipitação dos metais realizada no presente estudo, um efluente final contendo entre $4 \mathrm{e}$ $29 \mathrm{mg} / \mathrm{L}$ de ferro, e entre 27 e $54 \mathrm{mg} / \mathrm{L}$ de zinco foi obtido. A Deliberação Nor-

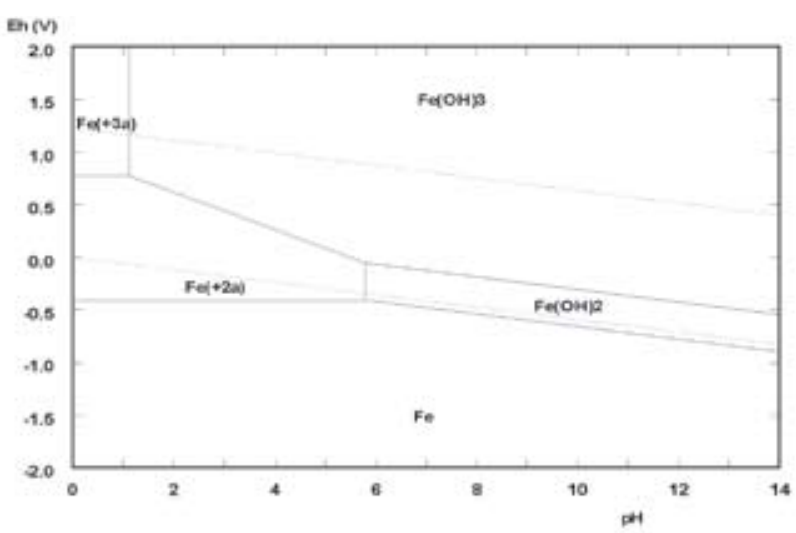

Figura 2 - Diagrama Eh-pH para o sistema $\mathrm{Fe}-\mathrm{H}_{2} \mathrm{O}$ (Fe total $=I \mathrm{~mol} / \mathrm{L}, 25^{\circ} \mathrm{C}$ )

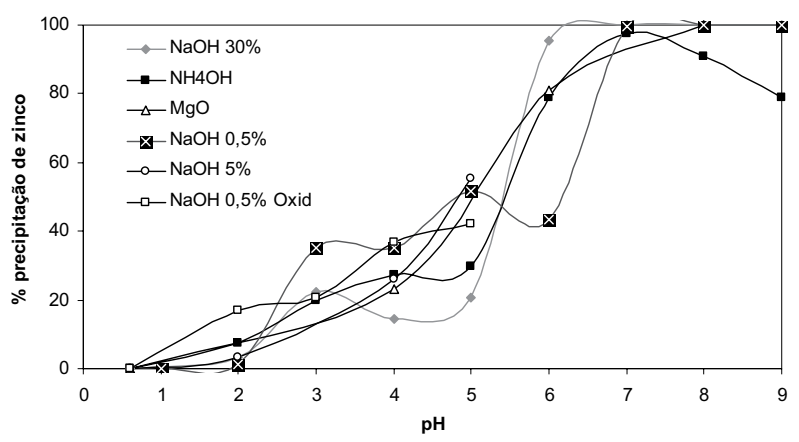

Figura 3(a) - Curvas de precipitação de zinco com agentes precipitantes diversos

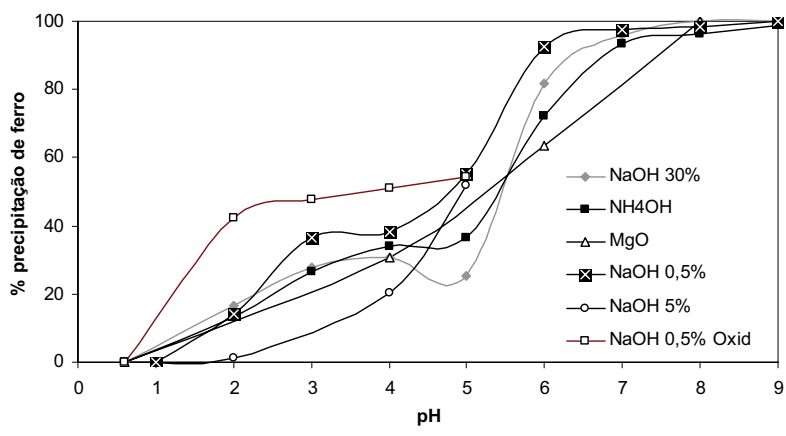

Figura 3(b) - Curvas de precipitação de ferro com agentes precipitantes diversos

mativa 10/86 do COPAM-MG estabelece limites de concentração iguais a $10 \mathrm{mg} / \mathrm{L}$ de ferro solúvel e $5 \mathrm{mg} / \mathrm{L}$ de zinco para o lançamento de efluentes nas coleções de águas de classes 1 a 4. Para o tratamento do efluente, portanto, a condição ótima ainda deve ser estabelecida.

As lamas produzidas pelos tratamentos com as soluções de hidróxido de sódio foram sempre mais espessas e de difícil sedimentação em decorrência da baixa velocidade de decantação. A utilização do $\mathrm{MgO}$ como agente alcalinizante propiciou a formação de menores volumes de lama, que se apresentou muito mais compacta, enquanto que a solução de $\mathrm{NH}_{4} \mathrm{OH}$ gerou um precipitado gelatinoso de difícil filtragem, coerentes com o apresentado na literatura (Ribeiro e Rocha, 2006). Um resumo comparativo das condições operacionais finais, além das características da lama e do efluente tratado (tipo 1), para cada agente precipitante empregado (exceto $\mathrm{NH}_{4} \mathrm{OH}$ ), é apresentado esquematicamente na Tabela 2. Como um dos objetivos do trabalho é obter uma separação seletiva mais eficiente para zinco e ferro, são avaliadas, a seguir, as técnicas de cristalização e de extração líquido-líquido. 
Tabela 2 - Comparação entre os agentes precipitantes estudados

\begin{tabular}{cccc}
\hline $\begin{array}{c}\text { Agente } \\
\text { precipitante }\end{array}$ & pH final do efluente & $\begin{array}{c}\text { Concentração após } \\
\text { tratamento (mg/L) }\end{array}$ & Características da lama formada \\
\hline $\begin{array}{c}\mathrm{NaOH} \\
(50 \% \mathrm{p} / \mathrm{v})\end{array}$ & 9,0 & Fe: 4,2 MG/L & Muito espessa, não sedimenta, de coloração \\
$\mathrm{CaO}$ & Estabiliza em pH 6,0 (atinge $\mathrm{pH}$ & Fe: $29,0 \mathrm{mg} / \mathrm{L}$ & Não sedimenta, menos compacta que a \\
& 11,5 após 9 horas de agitação) & Zn: $36,6 \mathrm{mg} / \mathrm{L}$ & lama gerada com MgO \\
$\mathrm{MgO}$ & 8,0 & Fe: $23,8 \mathrm{mg} / \mathrm{L}$ & Sedimentação lenta, lama mais compacta \\
& & Zn: $54,0 \mathrm{mg} / \mathrm{L}$ & que a de CaO
\end{tabular}

\section{Cristalização}

A recuperação de sais de zinco e ferro contidos em licores de decapagem é extremamente desejável, uma vez que reduz os volumes de efluentes a serem tratados e propicia um retorno econômico favorável do processo, por possibilitar a geração de subprodutos de substancial valor econômico, como é o caso tanto do cloreto de zinco quanto dos cloretos de ferro. Ozdemir et al (2006) realizaram uma análise econômica para a recuperação de cloreto ferroso a partir de soluçôes de decapagem. Esses autores avaliaram três esquemas básicos, a saber, (i) a adição de ferro metálico ao licor, visando converter o ácido residual em cloreto ferroso e sua posterior cristalização; (ii) a evaporação e o reciclo de grande parte do ácido não utilizado, e (iii) a cristalização direta do cloreto ferroso e posterior reuso do ácido. Os resultados indicaram uma maior rentabilidade para as duas primeiras alternativas, mas os autores ainda sugerem que a cristalização é uma alternativa interessante se comparada ao não tratamento da solução.

O licor em estudo apresenta zinco e ferro em elevadas concentrações. Assim, buscou-se uma separação seletiva destes metais por cristalização, uma vez que o cloreto de ferro e o cloreto de zinco apresentam uma substancial diferença em suas curvas de solubilidade, como apresentadas na Figura 4. Tem-se que um expressivo grau de separação pode ser alcançado através da cristalização fracionada do cloreto ferroso tetrahidratado, uma vez que o mesmo é mais insolúvel do que o cloreto de zinco. No caso do tratamento do efluente tipo 1 por cristalização, observou-se que a formação do cloreto ferroso, cristais levemente esverdeados, após a evaporação de $40 \%$ do volume inicial do efluente. A análise química do sólido formado não indicou a presença de zinco no mesmo, sendo este, portanto, de elevada pureza. Após a secagem destes cristais em estufa, verificou-se a ocorrência de um certo grau de oxidação do cloreto ferroso em cloreto férrico, cuja formação foi indicada visualmente pela coloração marrom avermelhada dos cristais. Para uma evaporação de 60\% do volume inicial do licor, os cristais formados já apresentaram certo teor de zinco, indicando, pois, a formação do cloreto de zinco.

Ensaios de cristalização fracionada em sistemas mais controlados, com mistura eficiente, monitoramento da variação de densidade e concentração da solução, podem propiciar a obtenção de resultados ainda melhores. A aplicação dessa técnica como etapa intermediária do processo requer uma pré-avaliação de custos, uma vez que o gasto de energia na evaporação pode ser significativo. A evaporação a vácuo deve também ser avaliada, uma vez que possibilita o trabalho em temperaturas mais baixas. Recomenda-se, também, que se faça o reaproveitamento do ácido e da água evaporados.

\section{Extração líquido-líquido}

O TBP (fosfato de tributila) é o extratante mais conhecido da família dos reagentes organofosforados que atuam por solvatação e tem sido largamente usado na separação de vários metais, tais como urânio, zinco, ferro, terras raras, dentre outros. A extração do metal se dá pela substituição da camada de hidratação da espécie metálica neutra presente na fase aquosa. Segundo Ritcey e Ashbrook (1984), a extração de metais de vários meios ácidos com TBP envolve, geralmente, duas moléculas de TBP que solvatam espécies neutras do metal. Neste caso, o TBP é muito efetivo como extratante para zinco presente em soluções ácidas clorídricas de decapagem, já que esta espécie se apresenta, nas condições do efluente tipo 1 sob a forma neutra como $\mathrm{ZnCl}_{2}$ (de acordo com cálculos de especiação química). Entretanto, nas extraçôes com TBP, verifica-se uma elevada transferência de moléculas de água para a fase orgânica em decorrência da solvatação das espécies metálicas (Grzeszczyk et al, 2007). Em compensação, uma solução extratante com elevada concentração de TBP $(80-100 \% \mathrm{v} / \mathrm{v})$ pode propiciar o alcance de elevadas eficiências de extração zinco e ferro, como observado por Rozenblat et al (2005). De acordo com estes autores, uma separação efetiva de zinco (II) e ferro (II) foi alcançada, mas não quando o ferro estava na sua forma mais oxidada, ou seja, sob a forma de ferro (III). Esses autores propuseram, então, a redução do $\mathrm{Fe}^{3+}$ presente no efluente para viabilizar a recuperação de zinco a partir de licores clorídricos provenientes da decapagem de metais, contendo $100 \mathrm{~g} / \mathrm{L}$ de $\mathrm{Zn}, 30 \mathrm{~g} / \mathrm{L}$ de Fe ${ }^{2+}$ e $2.5 \mathrm{M} \mathrm{HCl}$. Resultados similares também foram obtidos por Regel-Rosocka et al (2002).

O ferro presente no licor em estudo está majoritariamente na forma de ferro (II), o que dispensou a etapa de redução de ferro (III). Além disso, como a extração com TBP é seletiva ao zinco, que se apresenta em concentraçóes inferiores às do ferro no efluente, espera-se o que a separação $\mathrm{Zn} / \mathrm{Fe}$ com TBP resulte em menores custos operacionais. Os resultados da extração seletiva de zinco e ferro em concentrações variadas de TBP são apresentados na Figura 5. Verifica-se que zinco é preferencialmente extraído em detrimento do ferro, sendo que a quantidade de metal extraída, para ambos os metais, aumenta de forma praticamente linear com o aumento na concentração de extratante. Tem-se, por exemplo, que $60 \%$ do zinco e $10 \%$ do ferro são extraídos em uma única contactação utilizando-se $100 \% \mathrm{v} / \mathrm{v}$ de TBP, resultando em um licor contendo aproximadamente $30 \mathrm{~g} / \mathrm{L}$ de zinco e $80 \mathrm{~g} / \mathrm{L}$ de ferro. A separação, portanto, deve ser realizada em estágios, uma 
vez que o fator de separação $\mathrm{Zn} / \mathrm{Fe}$ encontrado nesta condição foi baixo $\left(\beta_{\mathrm{Zn} / \mathrm{Fe}}=14,0\right)$.

Uma vez demonstrada a possibilidade de separação $\mathrm{Zn} / \mathrm{Fe}$, fez-se necessário, então, determinar as melhores condições operacionais que maximizem a separação entre os metais. A Tabela 3 mostra os resultados para a extração de ambos os metais variando-se a relação O/A, utilizando-se uma fase orgânica contendo $100 \%$ de TBP. Observa-se que o aumento na relação $\mathrm{O} / \mathrm{A}$, ou seja, aumentando-se o volume de orgânico mantendo-se fixo o volume de aquoso $(20 \mathrm{~mL})$, favorece substancialmente a separação seletiva de zinco. Esse aumento se dá, também, no aumento na quantidade de zinco extraída. Tem-se, por exemplo, uma extração de zinco de $92,5 \%$ para $\mathrm{O} / \mathrm{A}=3$, com fator de separação $\mathrm{Zn} / \mathrm{Fe}$ em torno de 100 .

Os resultados indicam, portanto, que é possível tratar o efluente tipo 1 recuperando zinco e ferro de modo seletivo. Licores mais puros em zinco podem ser obtidos com a redução do ferro férrico, apesar de presente em baixa concentração, e a manutenção de condiçôes anaeróbicas no sistema, para evitar a oxidação do ferro ferroso presente na fase aquosa durante a realização da extraçãa. Apesar dos resultados favoráveis, é preciso otimizar, ainda, as condições operacionais de extração com relação ao efeito da temperatura, por exemplo. Além disso, a concentração de zinco no extrato pode ser elevada mediante a inclusão de estágios de lavagem, anteriores à etapa de regeneração do solvente (reextração) com soluções levemente ácidas (Ritcey e Ashbrook, 1984). A reextração do zinco presente na solução de TBP após a extração se mostrou viável com água, sendo necessária a operação em estágios.

Os resultados do presente trabalho, versando sobre a aplicação das três técnicas, precipitação química, cristalização e extração-liquido-líquido, podem ser utilizados em conjunto, na composição de uma rota de processo que viabiliza a recuperação de cloreto de zinco e de cloreto ferroso como subprodutos, bem como do ácido residual que pode ser reciclado ao processo de decapagem. A rota de processo seria então composta pelas seguintes etapas: (i) redução do ferro férrico a ferro ferroso; (ii) extração do zinco, utilizando-se TPB como agente extratante; (iii) cris-

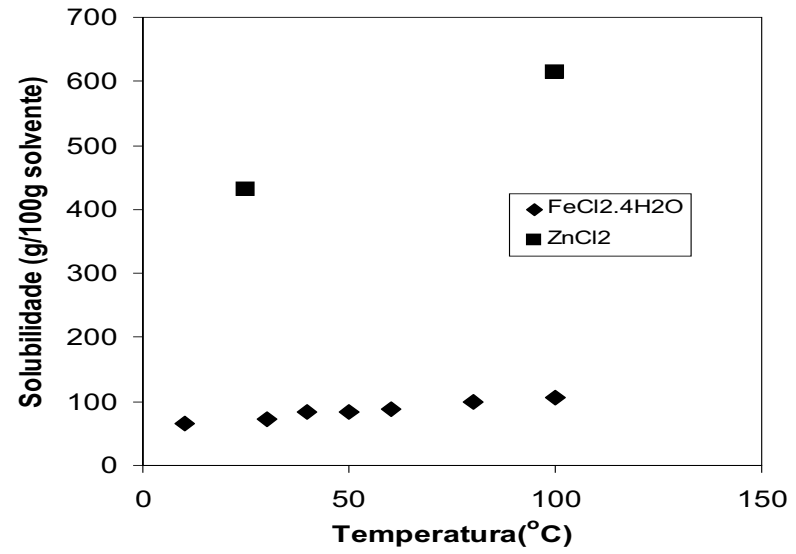

Figura 4 - Solubilidade do cloreto ferroso e cloreto de zinco em água em função da temperatura (Perry e Green, 1998)

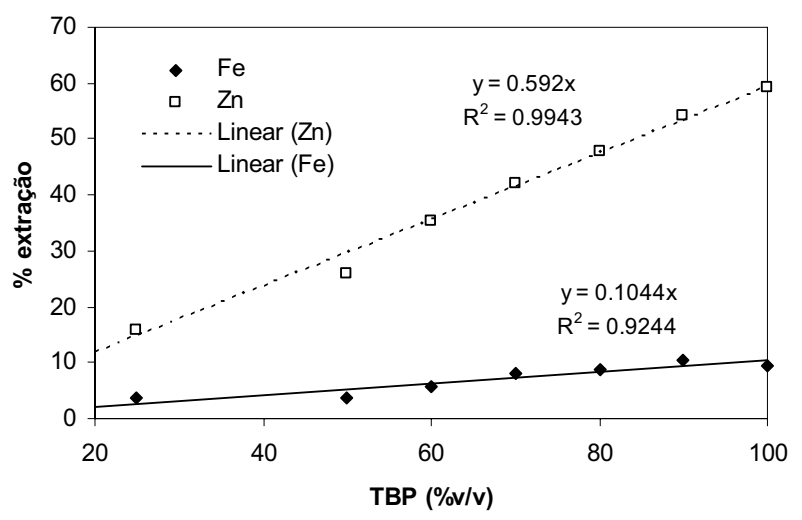

Figura 5 - Extração de zinco e ferro com TBP (razão $A / O=I, T=25^{\circ} \mathrm{C}$ )

Tabela 3 - Efeito da relação A/O na separação Zn/Fe com TBP puro

\begin{tabular}{cccc}
\hline Relação O/A & \% extração de $\mathrm{Zn}$ & \% extração de Fe & $\beta_{\mathrm{Zn} / \mathrm{Fe}}$ \\
\hline 0,5 & 40,9 & 7,1 & 9 \\
1,0 & 59,1 & 9,4 & 14 \\
1,5 & 74,8 & 8,5 & 32 \\
2,0 & 83,9 & 8,2 & 58 \\
2,5 & 89,5 & 9,5 & 81 \\
3,0 & 92,5 & 11,2 & 98 \\
\hline
\end{tabular}

talização do cloreto ferroso a partir da solução residual da extração do zinco (refinado), e (iv) reciclo da solução mãe à etapa de decapagem. Essa rota atende aos preceitos de produção mais limpa, norteadora dos processos industriais no século XXI, uma vez que reduz drasticamente o volume de efluentes e resíduos gerados no processo e, também, pode elevar significativamente o retorno econômico do processo.

\section{CONCLUSÕES}

Métodos alternativos para o tratamento de efluentes gerados pela indústria de galvanoplastia foram avaliados neste trabalho. Com base na avaliação realizada neste estudo, verificou-se que $60 \%$ das empresas deste setor, no estado de Minas Gerais, encontram-se localizadas na região metropolitana de Belo Horizonte. O estudo identificou 
dois efluentes com composição química distinta, a depender do porte e do processo empregado pela empresa visitada. Efluentes gerados por empresas de pequeno e médio porte gerados no processo de recobrimento por galvanização com zinco apresentam, em sua composição, zinco e ferro presentes em concentraçóes elevadas, em meio ácido clorídrico, tendo sido um efluente industrial desse tipo selecionado para tratamento pelas técnicas de precipitação, cristalização e extração líquido-líquido. A recuperação seletiva dos metais somente se mostrou possível por cristalização e extração líquido-líquido. A precipitação, ao contrário, mostrou-se adequada somente no tratamento do efluente. Uma alternativa de rota de processo conjunta, envolvendo a extração líquido-líquido do zinco com TBP como extratante e a cristalização de cloreto ferroso remanescente na solução residual (refinado), é vislumbrada com base nos resultados obtidos como viável tecnicamente para o tratamento do efluente investigado, resultando em aproveitamento dos metais sob a forma de sais, além de reuso da água.

\section{AGRADECIMENTOS}

Os autores agradecem o apoio financeiro do FINEP (Fundo Nacional de Desenvolvimento Científico e Tecnológico), CT Mineral 01/2001, e também aos Doutores Jeaneth dos Santos Benedetto, Carlos Antônio de Morais, Ana Cláudia Ladeira e Marília Camargos Botelho Fortes, do CDTN-CNEN (Centro de Desenvolvimento da Tecnologia Nuclear, Belo Horizonte, MG), pela participação conjunta no projeto durante o estudo do parque de galvanoplastia do estado de Minas Gerais.

\section{REFERÊNCIAS}

ABNT - ASSOCIAÇÃO BRASILEIRA DE NORMAS TÉCNICÁS, NBR 10.004: Resíduos Sólidos-Classificação. São Paulo, Brasil, 2004.

CIERPISZEWSKI, R. et al. Removal of zinc(II) from spent hydrochloric acid solutions from zinc hot galvanizing plants. Industrial Engineering Chemistry Research, v. 41, p. 598-603, 2002.

COPASA - Norma Técnica 187/2 - Lançamento de efluentes líquidos não domésticos na rede pública coletora de esgotos. Minas Gerais, Brazil, 2002.

CSICSOVSZKI, G., KÉKESI, T. AND TÖRÖK, T.I. Selective recovery of $Z n$ and $F e$ from spent pickling solutions by the combination of anion exchange and membrane electrowinning techniques. Hydrometallurgy, n. 77, p. 19-28, 2005.
US ENVIRONMENTAL PROTECTION AGENCY (EPA). Chemical Precipitation. US EPA, Washington, DC, 2000 (EPA832-F-00-018).

GRZESZCZYK, A., REGEL-ROSOCKA, M. Extraction of zinc(II), iron(II) and iron(III) from chloride media with dibutylbutylphosphonate. Hydrometallurgy, v. 86, n. 1-2, p. 72-79, 2007.

JANDOVÁ, J., MAIXNER, J., GRYGAR, T. Reprocessing of zinc galvanic waste sludge by selective precipitation. Ceramics - Silikáty, v. 46, n. 2, p. 52-55, 2002.

KURNIAWAN, T.A et al. Physico-chemical treatment techniques for wastewater laden with heavy metals. Chemical Engineering Journal, v. 118, p. 83-98, 2006.

OZDEMIR, T., OZTIN, C. AND KINCAL, N.S. Treatment of waste pickling liquors: Process synthesis and economic analysis. Chemical Engineering Communications, v. 193, n. 5, p. 548-563, 2006

PERRY, R.H., GREEN, D.W., PERRY'S. Chemical Engineers' Handbook. McGraw-Hill Int. Ed., Chemical Engineering Series, $7^{\mathrm{a}}$ ed., Nova York, EUA, 1998.

PETERS, R.W. et al. Crystal Size Distribution of Sulfide Precipitation of Heavy Metals. Industrial Crystallization, n. 84, 1984.

REGEL-ROSOCKA, M et al. Screening of reagents for recovery of zinc(II) from hydrochloric acid spent pickling solutions. In: Proceedings of The International Solvent Extraction Conference, Cape Town, South Africa, p. 768-773, 2002.

RIBEIRO, B.M., PAIM, T.S. ROCHA; S.D.F. Precipitation of heavy metals using magnesium based compounds. In: Proceedings of the XXII Interamerican Congress on Chemical Engineering, Buenos Aires, Argentina, em CD-ROM, 2006.

RITCEY, G.M., ASHBROOK, A.W. Solvent Extraction, Principles and Applications to Process Metallurgy, Part I, Elsevier, 361 p, 1984.

ROZENBLAT, M., REGEL-ROSOCKA, M., SZYMANOWSKI, J. Extraction of zinc(II) and iron(III) from spent pickling solutions of high zinc(II) content. In: Proceedings of The International Solvent Extraction Conference, Beijing, China, p. 1328-1334, 2005.

SCHUGERL, K., BURMASTER, T., GUDORF, M. Selective extractive recovery of metals from heavy-metal-hydroxy sludges of a pickling plant and galvanic processing. In: Shallcross, D., Paimin, R., Prvcic, L. (Eds.), Proceedings of the International Solvent Extraction Conference, v. 2, Melbourne, Australia, p. 1549-1552, 1996.

TERINGO III, J. Magnesium Hydroxide Reduces Sludge/Improves Filtering. Pollution Engineering, p. 78-83, Apr. 1987.

TOMASZEWSKA, M., GRYTA, M., MORAWSKI, A.W. Recovery of hydrochloric acid from metal pickling solutions by membrane distillation.eparation and Purification Technology, n. 22-23, p. 591-600, 2001.

WEI, X., JR., R.C.V. AND BUZBY, K.M. Recovery of iron and aluminum from acid mine drainage by selective precipitation. Environmental Engineering Science, v. 22, n. 6, p. 745-755, 2005.

$\mathrm{ZHOU}, \mathrm{P}$. et al. Heavy metal removal from wastewater in fluidized bed reactor. Water Research, v. 33, n. 8, p. 1918-1924, 1999.
Endereço para correspondência:

Sônia Denise Ferreira Rocha Departamento de Engenharia de Minas da Universidade Federal de Minas Gerais - UFMG

Rua Espírito Santo, 35 - Sala 7 I 7 30160-030 - Belo Horizonte - MG - Brasil

Tel: (03I) 3409-193I

Fax: (03I) 3409-1966

E-mail: sdrocha@demin.ufmg.br 